\title{
Study of micro electromagnetic bulging on a stainless steel foil
}

\author{
Qing-juan Zhao ${ }^{1,2}$, Chun-ju Wang ${ }^{1,2}$, Jie Xu ${ }^{2}$, De-bin Shan ${ }^{1,2}$, and Bin Guo ${ }^{1,2, *}$ \\ 1 School of Materials Science and Engineering, Harbin Institute of Technology, Harbin 150001, PR China \\ 2 Key Laboratory of Micro-systems and Micro-structures Manufacturing, Ministry of Education, Harbin Institute of Technology, \\ Harbin 150080, PR China
}

Received 1 February 2015 / Accepted 28 February 2015

\begin{abstract}
Electromagnetic micro-forming is a novel technology of micro-fabrication with high-energy rate which shows superiority in fabricating shallow and concave parts. In the research reported in this paper, micro electromagnetic bulging process was carried out with stainless steel foil, and the effects of discharge parameters and foil thickness on the deformation quality were analyzed. The results show that the surface quality and the forming depth of micro channels could be improved by increasing discharge energy and frequency. The discharge frequency has more effect on the micro electromagnetic forming quality. With the increase of the discharge frequency, the depth of micro channel reaches maximum value firstly and then decreases. The surface quality and depth of micro channel decreases with increase of the foil thickness. Optimum parameters arrays of micro channel with good surface quality and dimensional accuracy were obtained in the electromagnetic micro-forming of a stainless steel foil.
\end{abstract}

Key words: Electromagnetic micro-forming, Metal bipolar plate, Microstructure, Micro channel

\section{Introduction}

With the development of information technology, microelectro-mechanical systems (MEMS) and nanotechnology are widely used. All kinds of portable electronic products need to be improved on the miniaturization, concealment and high energy density of power supply. Fuel cell was the integration of micro power supply in MEMS system. It is a new type of micro energy with great potential compared with other micro powers. At present, most polar plates of proton exchange membrane fuel were made of graphite which accounted for $60 \% \sim 80 \%$ stack of the total weight and $30 \% \sim 45 \%$ of the total costs. Graphite polar plates were also difficult to work in harsh environment. All the problems above had become limitation in fuel cell industry $[1,2]$.

Sheet metal is more light and thin compared with graphite. So bipolar plate can be greatly reduced in volume and weight and be suitable for mass production. Many scholars are interested in plastic deformation of bipolar plate, and its manufacturing method has been developed in past few years. Jiangsu University had studied the metal flow field plate accumulation forming method by means of finite element simulation combined with experiments. In this method, the micro forming die was along with the flow direction and gradually completed channel pressing [3].

Manufacturing method for proton fuel cell based on rolling forming was invented by Shanghai Jiao Tong University. Roll forming, connections of bipolar plate, size finishes, integration of punching and shearing could be achieved by this

\footnotetext{
*e-mail: guobin@hit.edu.cn
}

method [4]. Stainless steel bipolar plates with thickness of $0.1 \mathrm{~mm}$ were successfully prepared by Wuhan University of Technology through flexible deformation [5]. Tohoku University materials research manufactured metal bipolar plate of $\mathrm{Ni}$ based metallic glass under supercool state using hot pressure casting method [6]. American Virginia Federal University had formed metal bipolar plate by hydraulic bulging and pressure welding method [7]. These two processes could be finished with one step if the cathode and anode plates were in symmetric condition. The research in electromagnetic micro forming technology had just begun in China. In Huazhong University of Science and Technology, experiment and simulation studies of electromagnetic forming on foil plate process under strong pulsed magnetic field were carried out. A cupshaped micro part was gotten. Lu Xin in North China Electric Power University had begun a submicron micro volume plastic forming simulation and experimental study. The experimental results showed that forming friction size effect was significantly inhibited by electromagnetic force driving and the electromagnetic micro forming was an effective micro molding method. Taiwan Yuan Ze University formed metal bipolar plate by chemical corrosion and simulations for this process were also carried out using the finite element method. Zhang in Louisiana Tech University had made a nanostructured Fabry-Perot interferometer by MEMS technology [8]. Technology for deformed metal bipolar with low cost, high efficiency and mass production were needed in order to meet the demand of market. Electromagnetic pulse forming technology has obvious advantage in mass production, low cost and forming properties. 


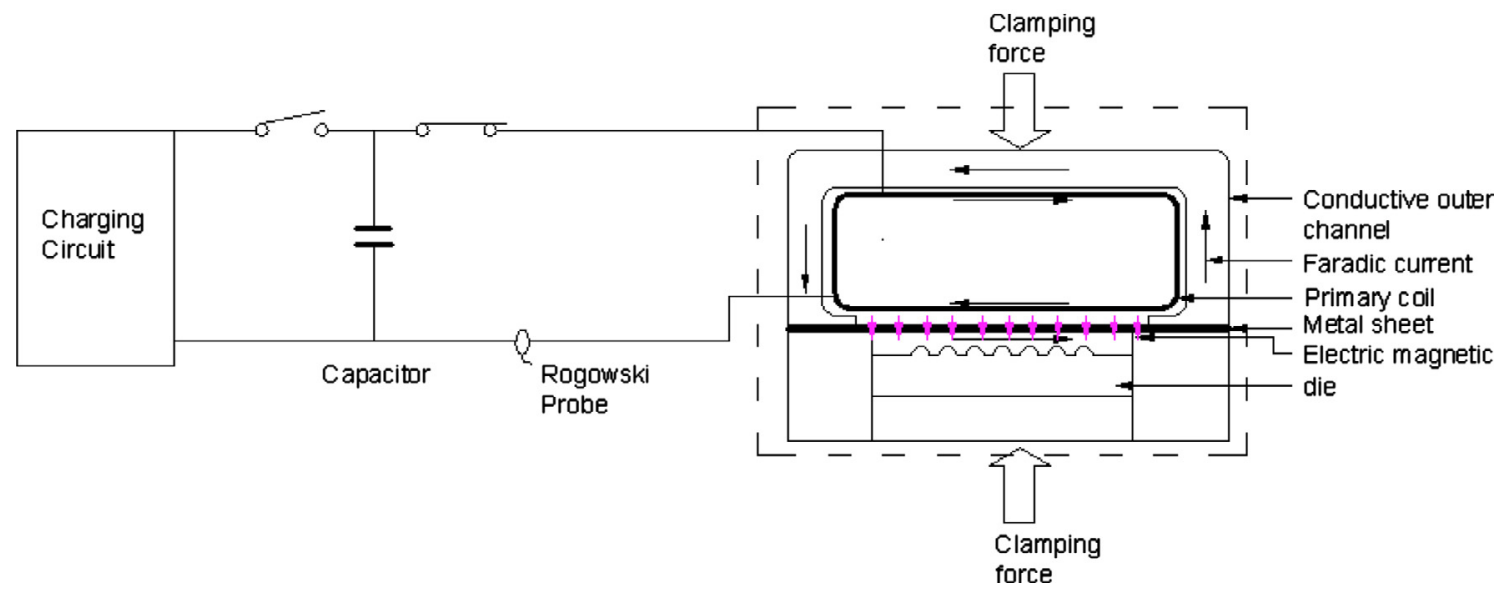

Figure 1. Schematic diagram of electromagnetic forming.
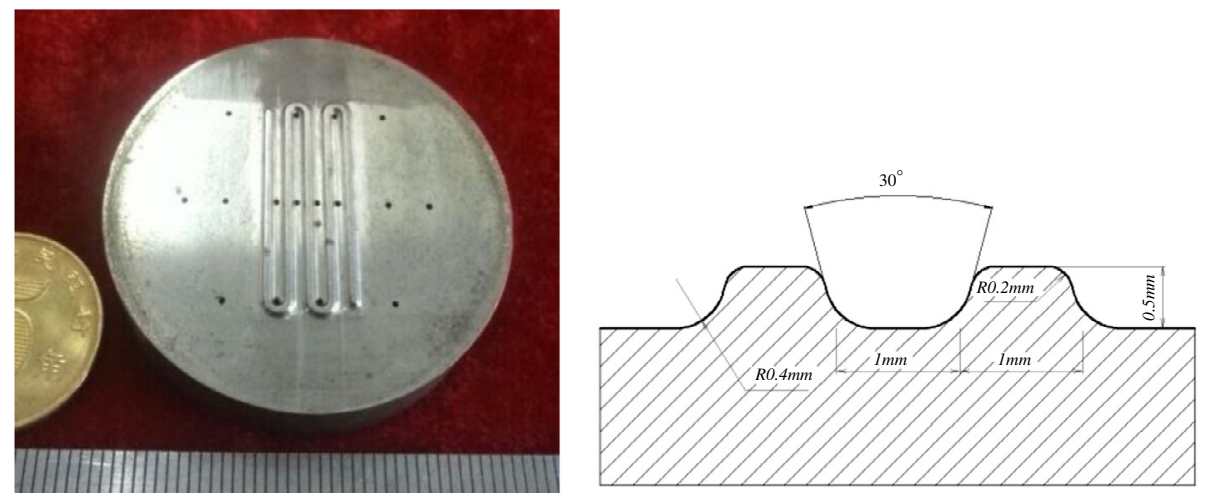

Figure 2. Schematic diagrams and dimensions of the bulging die.

Table 1. Discharge frequency and capacitance.

\begin{tabular}{lccc}
\hline $\begin{array}{l}\text { Capacitance } \\
(\mu \mathrm{F})\end{array}$ & $\begin{array}{c}\text { Frequency } \\
(\mathrm{kHz})\end{array}$ & $\begin{array}{c}\text { Discharge voltage } \\
(\mathrm{V})\end{array}$ & $\begin{array}{c}\text { Energy } \\
(\mathrm{kJ})\end{array}$ \\
\hline 768 & 2.679 & 3608 & 5.0 \\
112 & 2.187 & 2946 & 5.0 \\
1536 & 1.894 & 2551 & 5.0 \\
1920 & 1.694 & 2282 & 5.0 \\
\hline
\end{tabular}

In the research reported in this paper, SS304 stainless steel foil was selected as the experimental material by electromagnetic pulse forming technology. Influence electrical parameters and material parameters for deformation was analysed and the surface quality of bipolar plate also evaluated. The challenge is how to meet the cost and technical barriers of small parts molding. If conventional processing techniques could be scaled down, it would greatly promote the applications of micro parts.

\section{Electromagnetic forming technology}

Electromagnetic forming is a kind of technology which achieves plastic deformation with a high energy rate and short pulses. In this study, uniform pressure coils was adopted in the experiment to manufacture array micro channel with sheet metal, the basic theory of electromagnetic forming is

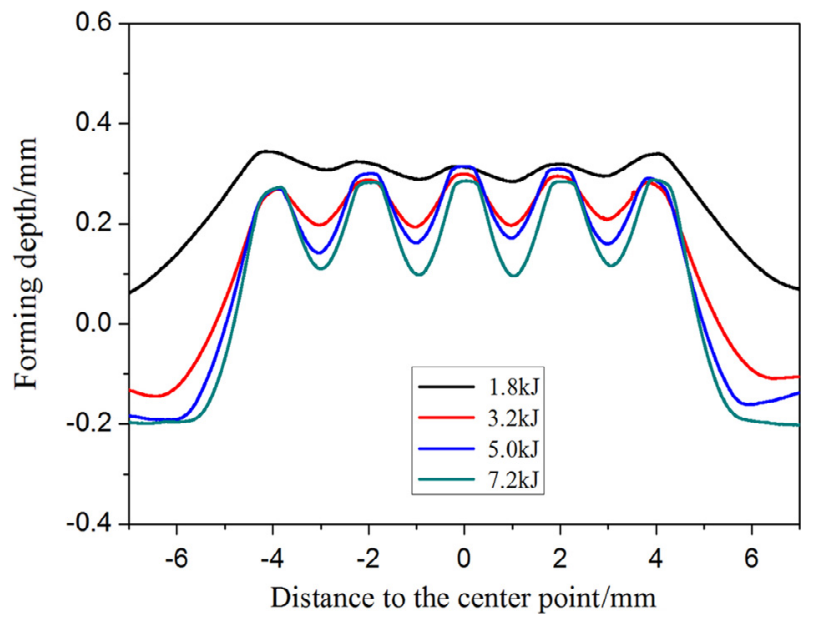

Figure 3. Relationships between discharge energy and forming depth.

electromagnetic induction laws in physics. Deformation schematic diagram is shown in Figure 1.

Outside coil were surrounded with a concave type conductor which is called outer guide box. The outer guide box forms a closed loop with the plate. When the charged capacitor releases energy, high-voltage pulse current flows through the pressure 


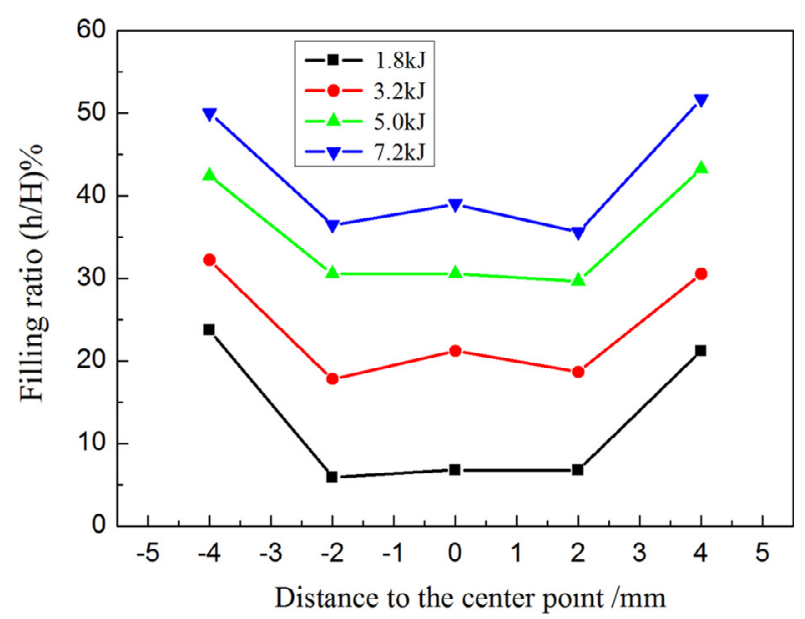

Figure 4. Forming depth of micro channels under different levels of discharge energy.

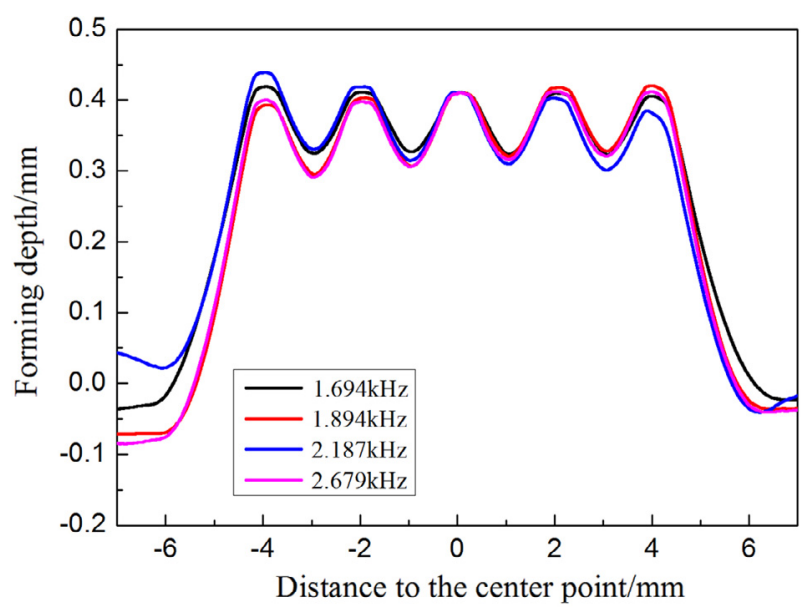

Figure 5. Relationships between discharge frequency and forming depth.

coil. At the same time, an induced current in the opposite direction forms in a closed loop. Blank with a high speed moves towards the mold surface under magnetic force, according to Faraday's electromagnetic law, and the channel network is replicated in the metal sheet through the plastic deformation.

\section{Experiment}

EMF3 0/5-IV and the EMF-20 type magnetic pulse forming machine were used as experiment equipment. Mold structure and micro channel are shown in Figure 2.

In this experiment, the mold material was $\mathrm{Cr} 12 \mathrm{MoV}$ steel and it was cut by an $\mathrm{CNC}$ wire-cutting machine and the characteristic structures were polished by a precision mechanical machining process. The surface roughness was $\mathrm{Ra} 0.1$. The hardness of mold after quenching was $60 \sim 62 \mathrm{HRC}$. Stainless steel sheet with thickness of $100 \mu \mathrm{m}$ annealed was selected as experimental materials. Because the stainless steel resistivity was relatively low, high conductivity copper

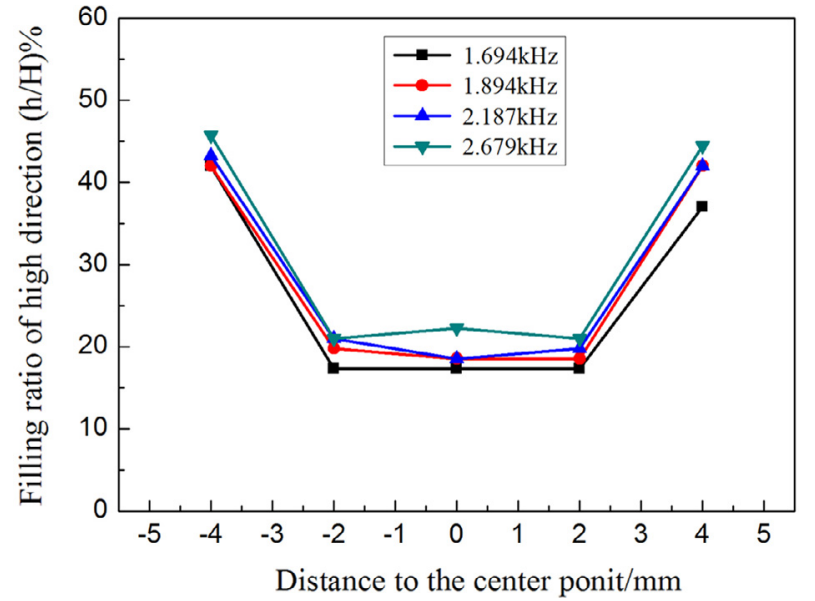

Figure 6. Forming depth of micro channels under different discharge rates.

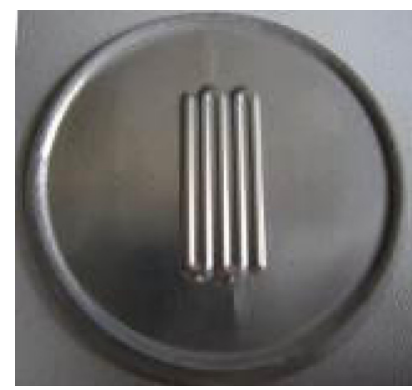

Positive surface

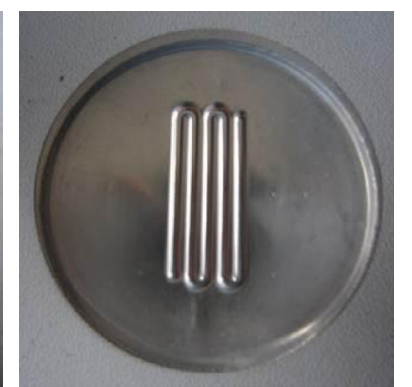

Positive surface
Figure 7. Micro channels obtained under $7.2 \mathrm{~kJ}$ discharge energy.

with thickness of $0.16 \mathrm{~mm}$ was used as auxiliary forming increasing thickness of plate. Talysurf PGI 1240 profiler were used to measure the section of micro channel, scanning electron microscope was used to measure micro topography on the surface.

Different discharge frequency discharge circuit parameters are shown in Table 1, in the first period electromagnetic forming process, plastic deformation has been completed in the first quarter of the discharge cycle, so the magnetic pressure payload time $T / 4=1 / 4 \mathrm{f}$.

\section{Results and discussion}

\subsection{Effect of discharge energy}

In electromagnetic micro forming process, the discharge capacitor was $100 \mu \mathrm{F}$, the discharge energy was $1.8 \mathrm{~kJ}$, $3.2 \mathrm{~kJ}, 5 \mathrm{~kJ}$ and $7.2 \mathrm{~kJ}$ respectively. Sections of micro channels produced under different levels of the discharge energy were measured with a profiler. Relationships between discharge energy and forming depth are shown in Figure 3.

The test results showed that the depth of micro channel was increased with the increased discharge energy in micro bulging 

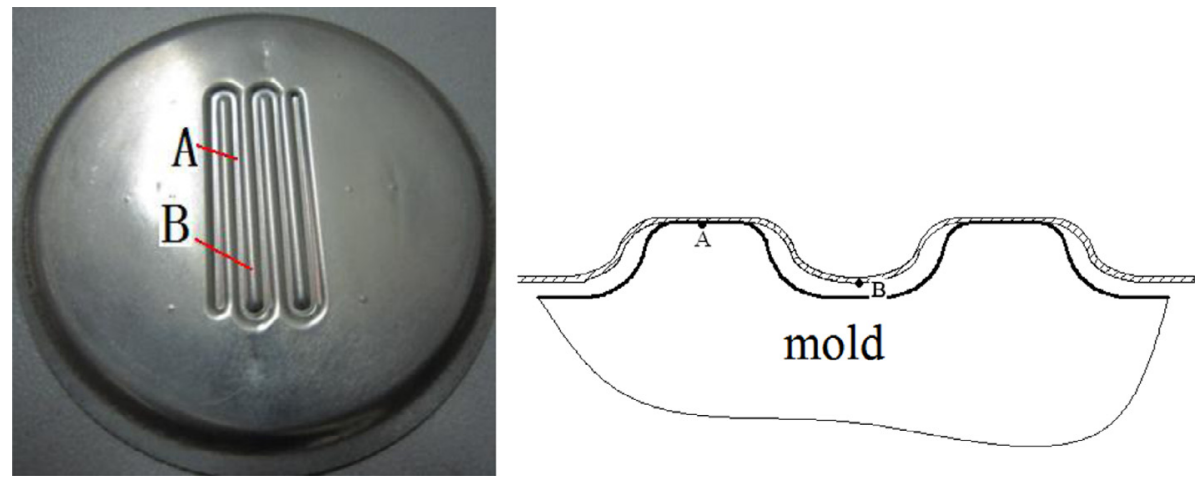

A - impacted area; B - free bulging region

Figure 8. A tested sample.
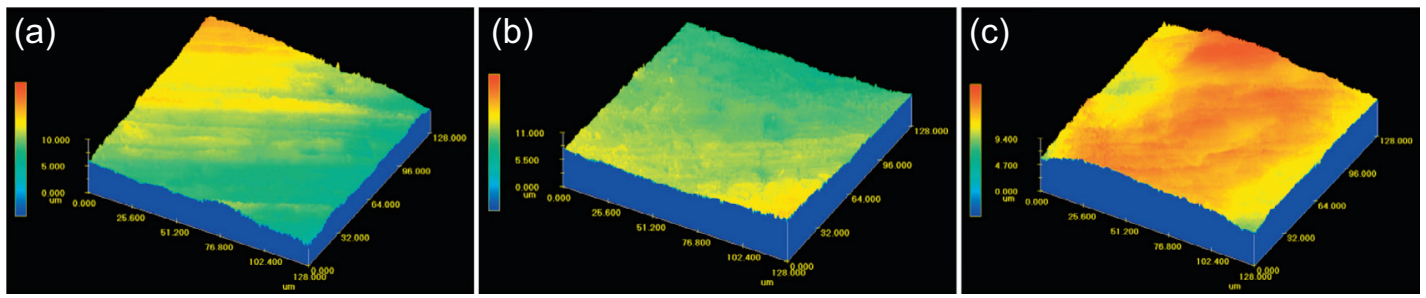

Figure 9. 3D surface topography of different regions for (a) Original sheet metal, (b) impacted area, (c) free bulging region.
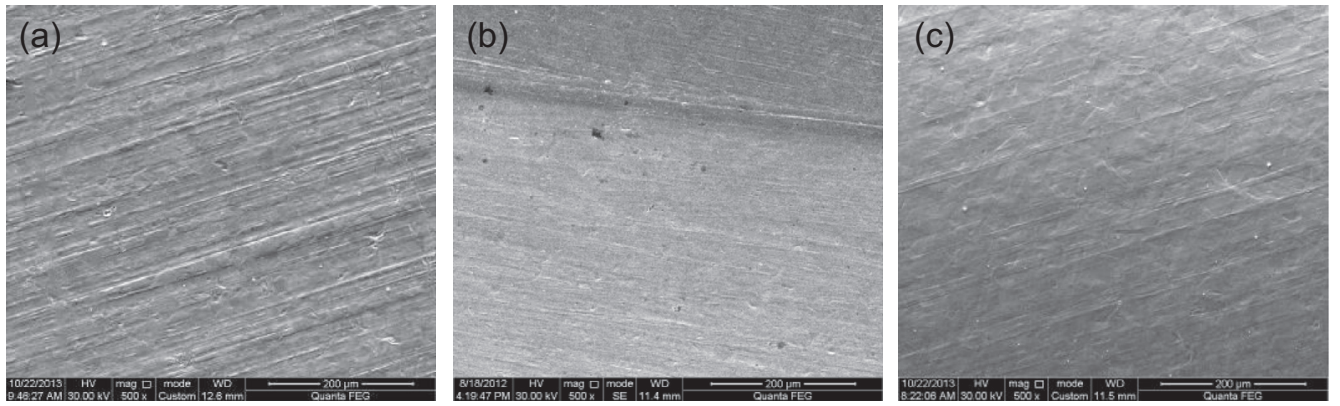

Figure 10. SEM micrograph of SS304 (500×). (a) Original sheet metal, (b) impacted area, (c) free bulging region.

experiment. In the electromagnetic forming process, the magnetic pressure of blank was determined by the discharge energy. The magnetic loads of deformation areas were increased rapidly with the discharge energy. Thus, the magnetic loading of blank was low under lower discharge energy which was not enough to achieve the deformation depth in bulging experiment. In Figure 4, the filling ratio of the formed depth $\mathrm{h}$ of micro channels to mould depth $\mathrm{H}$ increased with increasing of discharge energy which was caused by the changed amplitude of magnetic pressure. Increased discharge energy improved the forming depth.

\subsection{Effect of discharge frequency}

When the discharge energy was $5.0 \mathrm{~kJ}$, discharge frequency $2.679 \mathrm{kHz}, 2.187 \mathrm{kHz}, 1.894 \mathrm{kHz}$ and $1.694 \mathrm{kHz}$ respectively, effects of discharge frequency on the bulging depth of a bipolar pate were investigated, and the results are shown in Figures 5 and 6.
In Figure 7, micro channels with clear outline and good surface quality were obtained when the discharge energy was $7.2 \mathrm{~kJ}$ and the frequency $2.679 \mathrm{kHz}$. The results showed the discharge frequency had little effect on the bulging depth. Forming depth of micro channel reached the maximum value when the frequency was $2.679 \mathrm{kHz}$.

The main reason is that for a magnetic pressure amplitude of the discharge period would increase with increase of discharge frequency. Therefore, when energy utilization rate was increased, the forming depth was also increased.

\subsection{Effect of electromagnetic forming on the material surface}

A deformed part which is under a strong electromagnetic force and a high speed moves to the mold surface, and the surface topography and roughness is then changed. Surface laser confocal microscope and scanning electron microscope were used to observe the surface of different regions, as shown in 


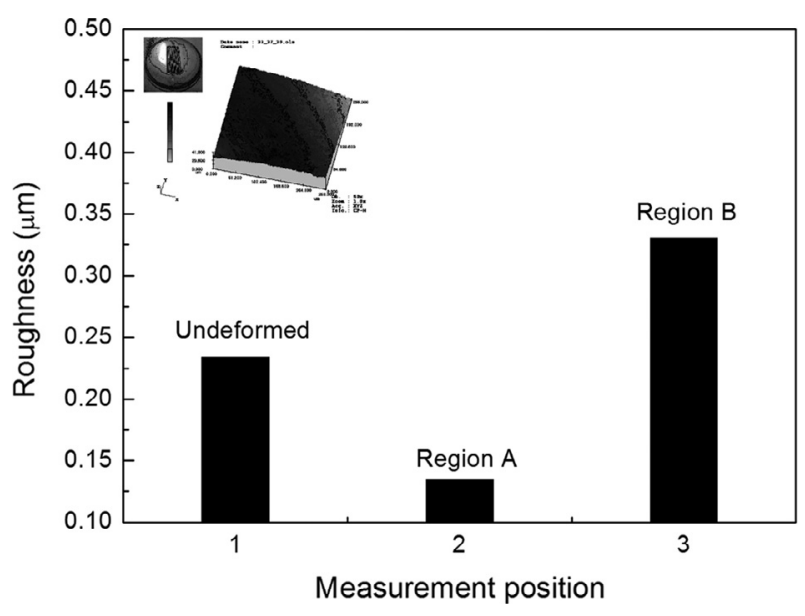

Figure 11. Effect of electromagnetic forming on the surface roughness.

Figure 8. Original sheet area, impacted area and free bulging area are shown in Figure 9. The bipolar pate had a clear contours and better surface quality when the discharge energy was $7.2 \mathrm{~kJ}$. The results showed that there were obvious rolling traces on original parts shown in Figures 9 and 10. But there were no obvious rolling traces on impact area of deformed parts. The parts surface was smooth, bright and clean as shown in Figures $9 \mathrm{~b}$ and $10 \mathrm{~b}$, in free bulging area; surface texture is stretched, waviness increases, and uneven surface becomes rough, as shown in Figures 9c and 10c.

Original sheet area, impacted area and free bulging area were measured by laser scanning confocal microscopy as shown in Figure 11. The results show that the surface roughness value at the impacted area $\mathrm{A}$ is reduced from $0.23 \mu \mathrm{m}$ of the undeformed foil to $0.13 \mu \mathrm{m}$. However, the surface roughness on the free bulging area $\mathrm{B}$ is increased to $0.33 \mu \mathrm{m}$. Thus the surface roughness of impacted area is reduced significantly, while the roughness of free bulging region is increased, compared to the original sheet area, after micro electromagnetic forming.

In this experiment, the mold-surface roughness was Ra 0.1 . It was showed that mold surface roughness had little effect on the bipolar plate impacted area. The results have been analyzed and the changes in surface morphology and surface roughness were caused by electromagnetic forming, in which the surface of the material touched with the mold surface with a high speed due to which its roughness decreased greatly. The freebulging area becomes rough partly in relation to the orientation and sizes of the surface grains created by sheet rolling when the raw material was produced.

\section{Conclusions}

Forming depth of the micro channels increases with the increase of discharge energy which is caused by the change of the amplitude of magnetic pressure. Micro channels with clear outline and good surface quality were obtained when the discharge energy was $7.2 \mathrm{~kJ}$. Frequency had little effect on the forming depth and width, and channel deformation was slightly increased as increased frequency. Forming depth of the micro channel reached the maximum value when the frequency was $2.679 \mathrm{kHz}$. The surface of the undeformed SS304 foil has obvious marks from the rolling which then became lower and even flattened in the impacted area of the surface of the formed parts. For the sample parts tested, surface roughness $(R a)$ decreased from $0.234 \mu \mathrm{m}$ to $0.134 \mu \mathrm{m}$ after electromagnetic forming. In the free bulging area, the uneven surface roughness increased significantly to $0.331 \mu \mathrm{m}$, due to the stretched rolling marks and increased surface waviness.

Improving surface quality of the formed parts and enhancing plastic properties of the metallic materials to be used in electromagnetic forming will be two key development-needs in the future research. The magnetic-field stress and stressstrain relationships induced in the material also need to be studied in detail in order to determine the mechanism of corrosion and flow behavior of the metal foils.

Acknowledgements. This work was supported by the National Basic Research Program of China under Grant No. 2012CB934100 and the National Natural Science Funds under Grant No. 51375113.

\section{References}

1. K. Cowey, K.J. Green, G.O. Mepsted, et al., Portable and military fuel cells, Current Opinion in Solid State and Materials Science 8 (2004) 367-371.

2. C. Xie, J. Bostaph, J. Pavio, Development of a $2 \mathrm{~W}$ direct methanol fuel cell power source, Journal of Power Sources 195 (2010) 3407-3415.

3. B.F. Yin, J. Wang, Z.Y. Xu, et al., Chinese invention patent 201010101119.X (2010).

4. J. Ni, X.M. Lai, S.K. La, et al., Chinese invention patent 200610118899.2 (2006).

5. Y. Liu, L. Hua, Fabrication of metallic bipolar plate for proton exchange membrane fuel cells by rubber pad forming, Journal of Power Sources 195 (2010) 3529-3535.

6. M. Yokoyama, S. Yamaura, H. Kimura, et al., Production of metallic glassy bipolar plates for PEM fuel cells by hot pressing in the supercooled liquid state, International Journal of Hydrogen Energy 33 (2008) 5678-5685.

7. M. Koç, S. Mahabunphachai, Feasibility investigations on a novel micro-manufacturing process for fabrication of fuel cell bipolar plates: Internal pressure-assisted embossing of microchannels with in-die mechanical bonding, Journal of Power Sources 172 (2007) 725-733.

8. T.H. Zhang, Z.G. Gong, R. Giorno, L. Que, A nanostructured Fabry-Perot interferometer, Optics Express 18 (2010) 20282-20284. 